\title{
Study on Modelling Standardization of Double-fed Wind Turbine and Its Application
}

\author{
Xiang Li, Yongning Chi, Haiyan Tang and Linjun Wei \\ China Electric Power Research Institute, Beijing, China
}

\begin{abstract}
Based on the standardized modelling of the International Modelling Team, study on double-fed induction generator (DFIG) wind turbine is processed in this paper, aiming at capability of universally and reasonably reflecting key performance related to large scale system analysis. The standardized model proposed is of high degree of structural modularity, easy functional extension and universalization of control strategy and signal. Moreover, it is applicable for wind turbines produced by different manufacturers through model parameter adjustment. The complexity of the model can meet both needs of grid-connected characteristic simulation of wind turbine and large scale power system simulation.
\end{abstract}

\section{Introduction}

The planning and operation of large interconnected electric power system need analysis and computer simulation every day. Power system planners and operators evaluate the potential impact of credible emergency plans and also the capability of power system in bearing these incidents and maintaining its stability and interconnection, by using simulation study. To ensure reliable and correct evaluation and minimize investment cost, power system model shall be able to reasonably present the actual performance of the equipment in its simulation. In terms of safe and stable operation of power system, an accurate electromechanical transient model of wind turbine is needed for analysing various operation modes of the power grid. In the past, most wind turbine models were developed by wind turbine manufacturers and software suppliers, to be as the special models for users to program on them. Generally speaking, these models, as object files, can only be read by software, while users cannot read the source code.

But, to integrate the user programming model in-to large interconnected power system network mod-el may bring multiple problems. Firstly, when adopting the models developed by individual users and companies, it is difficult to investigate whether the development of these models can accurately reflect the characteristics of wind turbines in various working conditions; secondly, since these user-specific models are usually in the mode of "black box", users cannot check it and moreover, special models highlight differently on time scale and exterior features. Thus, it is difficult for users to understand the features of the models profoundly, which would be disadvantageous for system study and brings more stringent requirements on model maintenance and upgrade; thirdly and most importantly, the models established by wind turbine manufacturers are often based on different software versions. When a large wind farm consists of different types of wind turbines of different manufacturers, study on power system stability would be extremely complicated and difficult.

In order to gain a transient model of wind turbine used for power system stability study, which can accurately and reasonably reflect the characteristics of grid-connected wind turbine in real cases and provide powerful support for power system stability analysis, working groups have been set up internationally for developing a universal model of wind turbine. Based on the standardized modelling of the International Modelling Working Group, this paper processed study on double-fed wind turbine, aiming at "capability of universally and reasonably reflecting key performance related to large scale system analysis". The standardized model proposed in this paper is of high degree of structural modularity, easy functional extension and universalization of control strategy and signal. Moreover, it is applicable for wind turbines produced by different manufacturers through model parameter adjustment. The complexity of the model can meet both needs of simulation about the characteristics of grid-connected wind turbine and large power system simulation.

\section{Standardized Modeling of International Working Group}

\subsection{WECC wind turbine modelling}

In June 2005, North American Utility Wind Integration Group (UWIG), Institutes of Electrical and Electronics 
Engineers (IEEE), Sandia National Laboratories (SNL) and National Renewable Energy Laboratory (NREL) of the U.S. Department of Energy (DOE) have jointly studied and set up the WECC Wind Turbine Modeling Team. Most technical activities are accomplished collaboratively by Western Electricity Coordinating Council (WECC), WGMG and wind power dynamic characteristics working group of IEEE. This team has completed the study of Phase I in 2010 and issued the study report, WECC WIND GENERATOR DEVELOPMENT. In the report, four kinds of wind turbines were defined based on wind turbine technology, the basic model structure were proposed based on each kind of wind turbine and the model of sub-module of wind turbine was provided. Furthermore, the WECC Team has also put forward relevant proposals on basic parameters of wind turbine model, validation of wind turbine model, modelling and equivalent methods of wind farms in this report. But according to the analysis to the report, the model of wind turbine module proposed by WECC Team is mainly based on the technologies of specific wind turbine manufacturers. Thus, its universality needs to be further improved $[1,2]$.

\subsection{IEC wind turbine modelling}

The International Electrotechnical Commission (IEC) established a WG27 Team in October 2009 for wind power simulation model, to solve the issues involved in universal model development of wind turbines. This Team aims at seeking for model specification and validation procedure. Their expectation is to set up a standardized modeling method and model for wind turbines and wind farms (similar to regular generator model).

This Team divides their work into two parts: on one hand, stipulate the topological structure / concept / configuration of universal wind turbine in current market and also the method for modifying the model after introducing the topological structure / concept, aiming at developing and bringing forward a universal model for wind turbine and avoiding the constraint of any special software platforms; on the other, stipulate the topological structure / configuration of wind farms and bring forward the universal dynamic simulation model of wind farms, including wind farm control and auxiliary facilities.

IEC WG27 Team has accomplished IEC 61400-27-1 CD1: "Standard for Electrical Simulation Model and Model Validation of Wind Turbines" by early 2012 and submitted it for TC88's discussion. At present, IEC WG27 Team is focusing on standardized model of wind farms [3].

Some members of IEC Team are also the members of WECC, IEEE Teams and also NERC Special Team. Hence, IEC WG27 Team carries on some study outcomes of WECC Team in the standardized model of wind turbines and on this basis, improves and develops it. The three teams collaborate with each other with clear work division, in order to ensure maximum benefit for the global industry and share the acquired knowledge to the greatest extent, under the joint efforts of WECC and IEEE.

\subsection{Colour illustrations}

Currently running wind turbines mainly consist of the following four types: constant speed wind turbine, variable slippage wind turbine, double-fed variable speed wind turbine and full-power conversion wind turbine. Each type of wind turbine differs both in terms of topological structure and performance [4-10].

As one of the most predominant wind turbines in current market, type $\mathrm{C}$ wind turbine (Fig. 1) has integrated all the advantages of the above types of wind turbines and achieved some improvements in terms of power electronics technologies. The rotor of the woundrotor induction generators are connected with the power grid through an insulated gate bipolar transistor (IGBT) based power converter by back to back connection mode. The power converter can control both the amplitude and frequency of rotor current. About $40 \%$ of the power output is injected into power grid through this converter and the rest are directly through stator side. This design plan can achieve variable speed within $\pm 40 \%$ of the rated speed and then maximize wind energy capture. Such converter achieves decoupling control of active power and reactive power, can realize flexible voltage control without the need of installing a reactive power compensation device and also achieve rapid voltage recovery and abnormal voltage cross. Type $\mathrm{C}$ wind turbines are also equipped with a pitch control system [11-13].

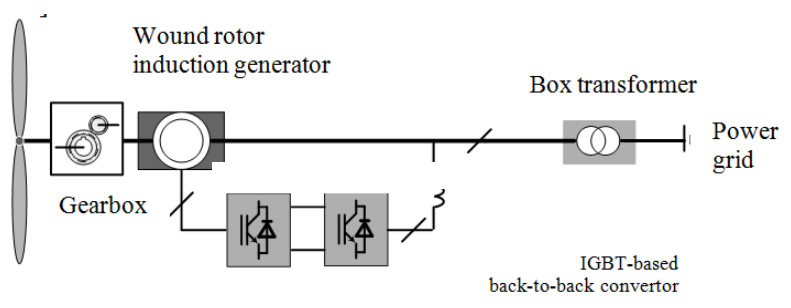

Figure 1. Topological structure of double-fed variable speed wind turbine.

\section{Study on standardized modelling for doubly-fed wind turbine model}

In the four model types of wind turbines, since the model of doubly-fed wind turbine contains both a motor model and a converter control model, its modeling is the most complicated. Usually, the sub-module of double-fed wind turbine model con-sists of aerodynamic module, maximum power tracking (MPT) module, pitch control, driving chain model, motor model, converter control and wind turbine protective module. The double-fed wind turbine model can be described with the help of the above modules, but these basic modules may neither be sufficient nor be necessary for the wind turbines of specific manufacturers. Besides, the processing strategies of sub-module models differ. Therefore, the standardized model of doubly-fed wind turbine shall be considered 
with accurate simulation of in-terconnection characteristics, procurability of pa-rameters and interface with power grid model.

As for the universal model studied and estab-lished currently which contains each basic sub-module of the double-fed wind turbine, its mod-el structure is consistent with that of the double-fed wind turbine proposed by IEC Team. The sub-module consists of aerodynamic module, shaft system double-mass model, pitch control, speed control and MTP module, motor model, converter control model and Crowbar protective module. Based on the latest study outcome of WECC and IEC, at this stage, we further study and modify rele-vant sub-module of the universal model of dou-ble-fed wind turbine, mainly including converter control and protection, shaft system and damping module, motor model and interface with power grid and aerodynamic model.

\subsection{Converter control and protection}

Converter control is a core part of wind turbine control. Normally, some major electrical functions and grid connected characteristics of wind turbines are achieved by converter control. Although converter control technologies of different wind turbine manufacturers differ and are regarded as extremely confidential technical information, as the development of wind turbine control technology and the adaptation to interconnection rule, the converter controls of different wind turbine manufacturers have more similar functional modules or electrical characteristics progressively. Thus, in the study on standardized modeling of wind turbine, converter model of wind turbine is an important part.

IEC WG27 Team will focus from the angle of the system on the converter control logic which influences exterior characteristics of wind turbines and provide a reference model. The converter control model proposed by IEC WG27 Team is given the following control logics, in addition to achieving active power and reactive power control under normal operation conditions:

(1) Voltage and reactive power control mode;

(2) Capability of injection of reactive power during a fault;

(3) Flow capacity limit of the converter during a fault; reactive power prioritized / active power prioritized;

(4) Amplitude limit and gradient limit of active power recovery after a fault resolved;

(5) Selection of torque reference during fault recovery;

(6) Whether reactive power compensating capacity possessed during fault recovery.

In the preliminary study, control models were established respectively for rotor-side converter and network-side converter of wind turbines. Rotor-side inverter is a double closed-loop structure of power outer loop/current inner loop. It achieves control over active power and reactive power of wind turbines in normal operation. The network-side converter is used to control DC link voltage and also the reactive power released by network-side inverter. Furthermore, in converter's control logic, the simulations of injection capacity of reactive current during a fault, recovery characteristics of active power after a fault (amplitude limit and gradient limit) and also flow capacity limit of a converter (reactive power prioritized) are given considerations to.

Based on the study outcomes of IEC WG27 Team and also on survey of the exterior characteristics of mainstreamed wind turbines domestically, our study added the simulation of reactive power compensating capacity during fault recovery and modified the simulation of active power recovery characteristics. The modified active power recovery characteristics can simulate the four types shown in Fig. 2. Thus, the universality of simulating the characteristics of different wind turbines is improved [16-18].

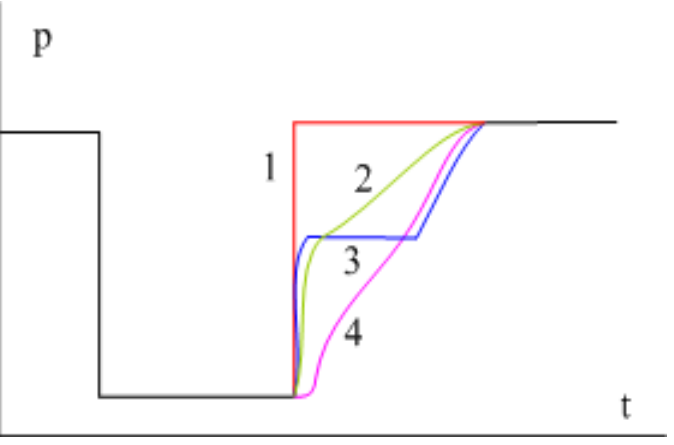

Figure 2. Different recovery characteristics of active power.

Converter control status of a wind turbine can usually be grouped to normal operation control mode, lowvoltage ride-through control mode and also uncontrollable mode under protection. In the working condition of normal operation, the control characteristics of active power and reactive power are subject to normal operation control mode; in case of machine-end voltage drop caused by power grid faults, wind turbines will enter into low-voltage ride-through control mode, with its operation characteristics subject mainly to relevant control logic of the converter; when a system fault leads to machine-end voltage drop and thus triggers protective actions, the rotor current of a wind turbine will enter into uncontrollable mode, with its operation characteristics subject to the protective actions.

\subsection{Shaft system double-mass model and its damping control}

During low-voltage ride-through of a wind turbine, the energy stored in a driving chain will be released to make oscillating component exist in the rotating speed of a generator. To better simulate the moment of force and rotating speed change of a wind turbine during voltage drop in power grid, while considering the order number of wind turbine model to be reduced, double-mass dynamic model is usually employed in electromechanical transient study to describe the driving chain.

WECC Modeling Team hold their view in the simulation study that, when a wind farm has multiple wind turbines, based on the analysis to electrical characteristics observed at grid connection points, the scattered distribution of wind turbines will have smoothing filtering effect on random perturbation of 
wind speed, but influences little the dominant shaft system oscillating components. When the frequency of the dominant shaft system oscillating components of $\mathrm{MW}$-wind turbines ranges in $2 \sim 5 \mathrm{~Hz}$, it is necessary to employ a double-mass driving chain model to evaluate its influence to the system.

In addition, to reduce damage to shaft system of wind turbines, some wind turbine manufacturers process rapid control by using power electronic technologies and design a damping link to restrict shaft system fluctuating component. The damping control technologies designed by different wind turbine manufacturers differ, are often regarded as patented technological secrets and will not be publicized. But since the damping control link influences distinctly the electrical characteristics of dominant shaft system oscillating components, WECC Modeling Team and IEC WG27 Modeling Team suggested simulation.

Meanwhile, WECC Team holds the view that, in stability study, wind turbine shaft system shall be employed with a double-mass mathematical model and the damping characteristics of the shaft system shall also be simulated. However, since wind turbine manufacturers regard it as technologically confidential when they employ control to improve shaft system damping, we can adjust system shaft damping coefficient for approximate fitting, instead of simulating active damping control technology.

\subsection{Aerodynamic model}

IEC WG27 Team proposed a universal modeling method for aerodynamic models. They aimed to avoid asking wind turbine manufacturers to provide their confidential parameter $C_{p}$ curve and also to achieve procurability of model parameters. Thus, they can simulate the mechanical power characteristics of a wind turbine, like linear model of traditional turbogenerators.

$\mathrm{C}_{\mathrm{p}}$ is the function of $\lambda$ and $\beta$. $\lambda$ can be expressed by the equation below:

$$
\lambda=\frac{\omega_{t u r} R}{V_{w}}
$$

Thus, when wind speed changes, to track wind speed change $\omega_{t u r}$ can achieve operation at the optimal working point $\lambda$.

For double-fed wind turbines:

$T_{\text {tur }} \cdot \omega_{\text {tur }}=T_{\text {gen }} \cdot \omega_{\text {gen }}=P$, and $\omega_{\text {gen }}=G \cdot \omega_{\text {tur }}$, where $G$ indicates the gear ratio of the gear box.

Therefore, double-fed wind turbines can track and control generator speed $\Delta \omega_{\text {gen }}$ by MPT modules to achieve maximum power tracking.

In the stability study of POWER SYSTEM, we often assume wind speed as constant; besides, since the inertia time constant of MW-level wind turbine rotor is often at second-level, generator speed change $\Delta \omega_{\text {gen }}$ is usually relatively small in electromechanical transient stability study process. Hence, $\Delta \lambda$ changes little in electromechanical transient stability study process. This means we can model the mechanical power $\mathrm{P}$ near the working points by linear method.

\subsection{Standardized model of a wind turbine}

Based on the work of experts in IEC and WECC Teams, the structure of double-fed wind turbine model should include :

$>$ Generator converter system module includes generator and converter models.

$>$ The control system module shall contain the main control system model of wind turbines.

$>$ Electrical equipment module includes gridconnected switch.

$>$ For wind turbines achieved low-voltage ride-through functions by installing a supporting device, we shall establish a simulation model of the installed device.

An interface of a wind turbine model shall at least include the following variables and parameters:

(1) Input variable:

1) Machine-end voltage of a wind turbine;

2) Operating speed of wind turbine; for types $C$ and $D$ wind turbines, wind speed input can be replaced by active power;

3) Reactive power or power factor order of wind turbine operation;

4) Controller order received by a wind turbine from a wind farm, e.g., active power and reactive power orders.

(2) Output variable.

1) Machine-end current of a wind turbine.

2) Active power of a wind turbine.

3) Reactive power of a wind turbine.

Based on the actual structure of wind turbine models, the output variables may also include: parameters of generators and mechanical driving systems, e.g., rotational inertia, generator speed or wind turbine speed, pitch and control parameter.

(3) Parameters that can be set:

1) Operation mode of wind turbines, e.g., voltage control mode, power factor control mode and reactive power control mode.

2) Model parameters to be adjusted in model simulation, e.g., operation mode parameter and controller parameter.

3) Rated model parameters;

4) Initial model parameters.

\section{Model comparisons}

We simulated the same system working conditions, set the same system faults and adjusted some parameters of the model; then, compared and analyzed the testing data and simulation results of some actual double-fed wind turbines under the working conditions of small load / full load; validated and compared the simulation curve and actual curve of machine-end voltage, active power and reactive power in the standardized model of a double-fed wind turbine proposed.

Fig. 3 illustrates the fitting result of the actual curve and simulation curve of a wind turbine in case of full load / three-phase short circuit fault / 20\% voltage drop. The diagrams show the per-unit values of machine-end voltage, active power and reactive power. 


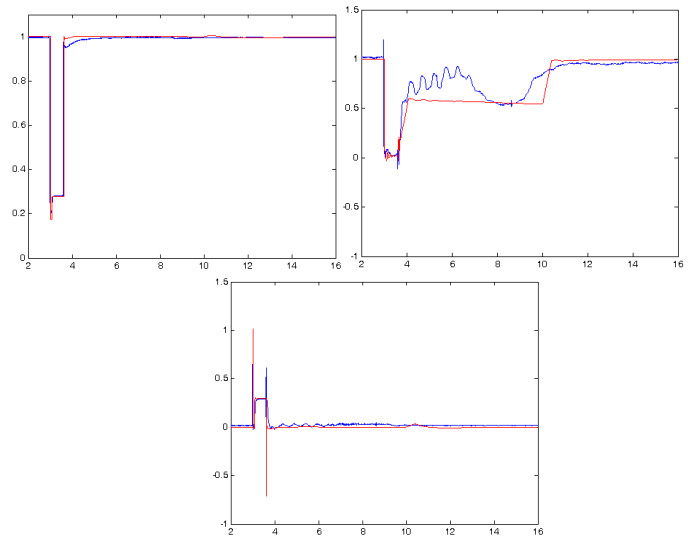

Figure 3. Comparison of actual and simulated curves of wind turbines with full load.

Fig. 4 illustrates the fitting result of the actual curve and simulation curve of a wind turbine in case of small load / three-phase short circuit fault / $20 \%$ voltage drop. The diagrams show the per-unit values of machine-end voltage, active power and reactive power.

The fitting results of actual curve and simulation curve show that, the fitting is good under small load, but there is distinct error in the fitting of active power characteristics under full load. Thus, local modules need to be modified based on a standardized model of a wind turbine, on the premise that detailed control strategies of wind turbine manufacturers are obtained.

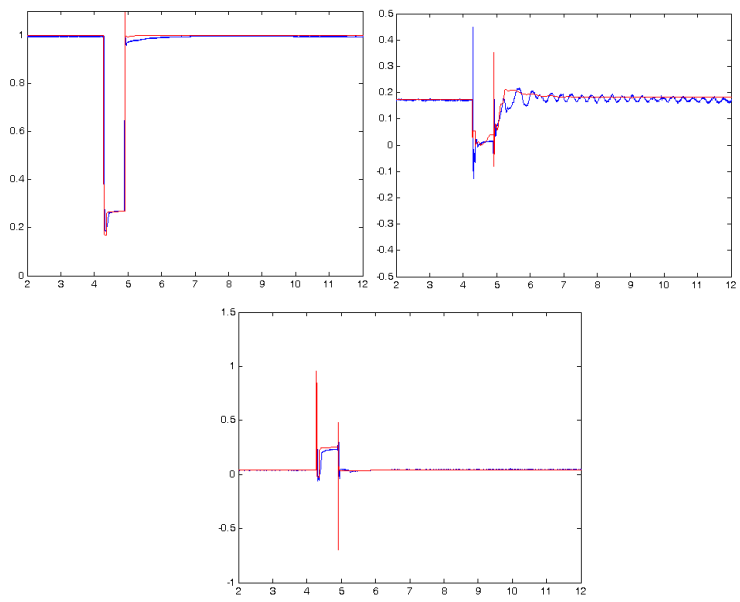

Figure 4. Comparison of actual and simulated curves of doublefed wind turbines with small load.

\section{Conclusion}

As constant increase of wind power scale in China, wind power has become the third largest power source after thermal power and hydropower. Thus, we need to process model standardization study to meet the simulation demand of great power grid and big perturbation. Moreover, we need to refer to the advanced experience overseas, promote our technology by standard and provide technical support for promoting our wind turbines in the global market, so as to make simulation models more accurately reflect the overall exterior characteristics of a wind turbine in various working conditions.

\section{Acknowledgements}

This work is sponsored by National Basic Research Program of China (973 program) under Grant 2012CB215105 and 2015 State Grid Corporation S\&T Project named Security Analysis and Research on Basic Technology of Protection under New Grid Development Situation.

\section{References}

1. WECC wind generator modeling group. No.NFT-111342-01 with NREL, proposed changes to the WECC WT3 generic model for type 3 wind turbine gen-erators model. USA: Electric Power Research Institute, (2013)

2. WECC wind generator modeling group No.NFT-111342-01 with NREL, proposed changes to the WECC WT4 generic model for type 4 wind turbine gen-erators model[S]. USA: Electric Power Research Institute, (2013)

3. IEC National Committees. 61400-27-1, Electrical simulation models for wind power generation[S]. International Electrotechnical Commission, (2013)

4. Liu Tao, Ye Xiaohui, Wu Guoyang, et al. An active power control model of wind power generating unit suitable for medium- and long-term dynamic simulation of power grid [J]. Power System Technology, 38(5): 1210-1215, (2014)

5. Boukhezzar B, Siguerdidjane H. Nonlinear control of a variable-speed wind turbine using a two-mass model [J]. IEEE Transactions on Energy Conversition, 26(1): 149-162, (2011)

6. Santoso S K, Thu L H. Fundamental time-domain wind turbine models for wind power studies [J]. Renewable Energy, 32(14): 2436-2452, (2007)

7. Lang Binbin, Mu Gang, Yan Gangui, et al. Research on wind speed vs output power characteristic curve of wind power generator interconnected with power grid [J]. Power System Technology, 32(12): 70-74, (2008)

8. Wang Songyan, Li Bijun, Yu Jilai, et al. Analysis on time-varying characteristics of probability error in fore-cast of wind speed and wind power [J]. Power System Technology, 37(4): 967-973, (2013)

9. Yang Lihui, Ma Xikui. Impact of doubly fed induction generator wind turbine on power system low-frequency oscillation characteristic, Proceedings of the CSEE, 31(10): 19-25, (2011)

10. Zhao Haoran, Wu Qiuwei, Ioanis Margaris, et al. Imple-mentation of IEC generic models of type 1 wind turbine generator in DIgSILENT/PowerFactory, Automation of Electric Power Systems, 33(8): 26-33, (2013)

11. Zhang Yanxia, Tong Rui, Zhao Jie, et al. Transient char-acteristics analysis and low voltage ride-through scheme of double-fed wind turbine generators. Automation of Electric Power Systems, 37(6): 7-11., (2013) 